\title{
Al in the noosphere: an alignment of scientific and wisdom traditions
}

\author{
Stephen D. Edwards ${ }^{1}$
}

Received: 18 May 2020 / Accepted: 25 May 2020 / Published online: 9 June 2020

(c) Springer-Verlag London Ltd., part of Springer Nature 2020

The international lockdowns are a reminder of the intimate interconnectedness of planet earth, as noted by Vernadsky and de Chardin, in their concept of noosphere (Bischof 2007; de Chardin 1959), or mind sheath emerging from the biosphere. Today, this includes enveloping technological communication and information systems, such as the internet, Skype, smartphones and Global Consciousness Project (Nelson 2011), which registers significant statistical effects in relation to notable global events, such as the death of Nelson Mandela, and international peace days. Whilst we anxiously await for a vaccine for Covid-19, many of us find solace and freedom of spirit in healing meditation and related reflections. Freedom to be what we are and to become what we can become. This guiding philosophy has always been sustaining when going through tough times or constraining conditions. Memories arise of Shakespearian quotes: "There's a divinity that shapes our ends, roughew them as we may" and "This above all, to thine own self be true" (Quotes from Hamlet and Polonius respectively). Other constraining situations in the past surface in relation to when the soul-in the sense of psyche-longs for freedom. Viktor Frankl, who survived as a Nazi prisoner of war, and noticed how survivors were those with meaning and/or purpose in life, remains a great resource.

Various studies indicate an interconnecting global information network facilitated through the earth's magnetic field (McCraty et al. 2018). The Institute of HeartMath, Global Coherence Initiative (GCI) includes ultrasensitive, magnetic field detectors, installed strategically around the planet, which currently provide correlational data in this regard. Current HeartMath focus is on raising human spirit. This reminded me that I first became involved with HeartMath, after noticing that it is essentially an update scientific version of perennial wisdom practices. From an African perspective,

Stephen D. Edwards

sdedward@telkomsa.net

1 Psychology Department, University of Zululand, Private Bag X1001, KwaDlangezwa 3886, South Africa it resonated with Woza Moya, the first step in an African SHISO, heart-breath workshop. Here SHISO, a traditional term of respect for a human being, is used as an acronym for Spirit (umoya), Heart (inhlizyo), Image (umcabango), Soul (umphefumulo), and Oneness (ubunye). The SHISO workshop takes the form of five steps, one for each letter of the acronym (Edwards 2019). Memories surface of research collaboration with Dr Rollin McCraty, Director of HeartMath Research Centre, which led to the installation of an African GCI magnetometer, at Bonamanzi Game Reserve in Zululand, in 2015. This is one of six magnetometers strategically placed around the planet for ongoing monitoring of global coherence. GCI data are particularly correlated with the electromagnetic field of the human heart and monitored through heart rate variability patterns, especially coherent heart rhythms and resonances (Edwards 2019; McCraty et al. 2018).

Here, I also reflect on my personal experience of meditation and healing practices, involving GCI and COVID-19, during lockdown in South Africa. This experience, as a part of a personal case study, involved the use of Global Coherence and Inner Balance apps to test the null hypothesis that healing meditations, as regular activities, were expected to incur no significant change. In the case study, the COVID-19 pandemic was regarded as the heuristic field, for investigation and intervention, to complement other local and global initiatives in research, instruction counselling, and integral health promotion. Two electronic devices, the HeartMath Global Coherence and Inner Balance apps, were used to measure meditation practices. I used the Global Coherence app for global coherence healing meditations and the Inner Balance app for shorter personal healing after physical exercise. The Global Coherence app is in beta phase testing at present. It records mean coherence levels at individual, group and global levels. Although Global Coherence mean scores are available per session, sessional data is continually updated, which means achievement data is unreliable for calculation purposes. The Inner Balance records coherence means and achievement totals, which are readily available per session. 
The case study investigated empirical and experiential information from these electronic devices. It required a mixed methods design, and differentiated perspectives, i.e., individual and collective, objective and subjective, researcher and participant (Fetters, Curry, and Creswell 2017; Lindhard 2019; Wilber 2000). By their very nature, the electronic devices, provided objective, quantitative, individual, collective and summative records of meditation sessions. The study integrated quantitative measurements, with qualitative descriptions of some experiences emerging from use of these devices, with their respective measuring, monitoring and biofeedback function. However, rigorous, transparent and objective one's attempts, critical reflexivity reveals many inevitable limitations of heuristic, phenomenological, autobiographical type, case studies, such as bias, expectations, assumptions, personal knowledge of instruments etc. These limitations are all readily acknowledged. Although case studies are unique, providing data that are not generalizable, they have advantages of facilitating original, detailed and in depth exploration of phenomena, experiences and events that may illuminate theory and stimulate further exploration.

The findings of the case study indicated rejection of the null hypothesis in favour of an alternative research hypothesis of healing consciousness. Integral, quantitative and qualitative findings indicated that the lockdown period was associated with highly significant meditation improvements. Findings supported and extended those of other similar studies and further scientific studies are indicated (Edwards 2019; McCraty et al. 2018). The reliability or accuracy of the electronic devices as AI measurements is a valid point of discussion in the present context. With regard to meditation phenomena, intuition trusts inner experience more than objective measurement. However, when in doubt, it is helpful to treat data along a yin yang scale, where each aspect balances the other. If the coherence level is higher than expectation, more credibility is given, raising the value allocated to the meditation. If the coherence level is lower than expected, this could lower the perceived value of the meditation phenomena apprehended. As the study constituted a response to COVID-19, the Global Coherence app demonstrated appropriate relevance.

It was decided to discuss and conclude this article after 3 weeks of lockdown for various reasons. Firstly, there was sufficient quantitative and qualitative data. Secondly, qualitative data had reached saturation point as some meditation phenomena became repetitive. Thirdly, the local Bonamanzi magnetometer went off line, potentially affecting local African correlational data. Although we were involved in monitoring and repair work, there was no indication as to how long this would take. Fourthly, Global Coherence meditation sessions, chosen as representative of the Lockdown meditations, kept in sequential order of their date, seemed to tell their own authentic story. Fifthly, most meditation data seemed to fall into two categories (a) actual meditation phenomena (b) reflection and clarification during data capture. Methodologically, such consciousness transformations also reflect the integral approach of including interior and exterior, or inside-out and outside-in perspectives (Lindhard 2019; Wilber 2000).

One meditation example deserves special mention. It focused on a videotaped communication for electronic transmission to local church parishioners, with its message of the heart as universal, integral, physical, emotional, mental, social, ecological and spiritual organ. The focus was on regular heart rhythm, which relates to renewing emotion, associated with any positive feeling, such as contented, peaceful, happy, loving, appreciative, grateful etc. Relaxation, resilience and resistance and general healing builds from such renewing feelings. For example, listening to the heart rhythm aligning with the glistening sounds of silence and surging sea profoundly amplified experiences of alignment with the all, or interconnectedness of everything. This pattern developed more or less at the same time as hearing of COVID-19. Some intuitive healing sense spoke of aligning with and cleansing polluted planet, contaminated atmosphere, and hopelessly lost humanity with its related, negative spin offs on all sentient beings. In such meditation, poetry may arise from heart-beat coherence and accompanying bliss, as one consciously uses the breath, like a violin fiddle playing upon the harmonic heart strings. This includes person-world relationships at the ecological level. At another psychophysiological level, the analogy is of the heart conducting the orchestra of the bodily systems, with all eventually singing in tune, as the level of meditation deepens. Then there is enhanced global reaching out in healing through electromagnetic radiations.

Assagioli (1985) and de Chardin (1959) are in accord in describing a supreme synthesis of the personal will with the universal will, a tuning in, and participating in the rhythms of universal life in all their planetary and cosmic energy. Such descriptions resonate with the HeartMath coherent moment of healing awareness and consciousness. In Indian and Chinese philosophy, terms such as sattva and wu-wei respectively apply. In my experience, HeartMath Global Coherence and Inner Balance apps are instrumental in enhancing this experience of supreme synthesis, stemming from spontaneous lengthening of the cardiorespiratory cycle at a time when aware of COVID-19. This intuitive, heartfelt, global healing response to distinct planetary needs, including greater global consciousness, international collaboration and sustained health promotion, was accompanied by intention to increase coherence and resonance. Certainly the observed increase in coherence, in both IB and GC biofeedback apps, indicating increased potential for global healing, served to continue this practice over lockdown. Similar 
findings have been observed in other studies using longer heart-breath cycles (Brown and Gerbarg 2009).

Meditation also teaches a perennial psychology as study and practice of finding the best way. Self-realization relates to the way in which inner experience becomes the guide for actions (Assagioli 1985; Edwards 2019). Integral life practice implies exercising body, mind and spirit in self, culture and nature (Wilber 2000). All components seemed relatively satisfied in this case study, with nature least so, as attested to by the increasing meaningfulness of a small clump of green foliage in a rockery, which became more prominent when running laps around the pool area of the apartment block. From an objective and collective perspective, the appreciation and revitalization of nature has been widely reported in the media. For survivors, suffering humanity and polluted planet, COVID19 could be one of many sorely needed "blessings in disguise" that serve to promote meditation, healing and ecology.

Clearly, large scale, scientific studies are needed to fully investigate correlational and causative patterns in relation to COVID-19 and Global Coherence Initiative magnetometers. From an everyday, healing perspective, the HeartMath approach is that deep heart wisdom provides ultimate answers for those who listen and hear. Patients ultimately tell healers of how to solve their problems. In traumatic times, such as COVID 19, AI may also assist with improved noosphere, deeper understanding and acting on environmental psychology, as well as psychological atmosphere, in an all-embracing form of energy science. In alignment with most scientific and wisdom traditions, COVID 19 reminds humanity of the vital importance of the everyday practice of power tools of the heart such as appreciation, forgiveness, non-judgement, peacefulness, care and love.

Curmudgeon Corner is a short opinionated column on trends in technology, arts, science and society, commenting on issues of concern to the research community and wider society. Whilst the drive for superhuman intelligence promotes potential benefits to wider society, it also raises deep concerns of existential risk, thereby highlighting the need for an ongoing conversation between technology and society. At the core of Curmudgeon concern is the question: What is it to be human in the age of the AI machine? -Editor.

\section{References}

Assagioli R (1985) The act of will. Penguin, Harmandsworth, Middlesex, England

Bischof M (2007) Vernadsky's Noosphere and Slavophile Sobornost. In: Beloussov LV, Voeikov VL, Martynyuk VS (eds) Biophotonics and coherent systems in Biology. Springer, New York, pp 279-297

Brown RP, Gerbarg PL (2009) Yoga breathing, meditation, and longevity longevity, regeneration, and optimal health: Ann N. Y. Acad Sci 1172:54-62. https://doi.org/10.1111/j.1749-6632.2009.04394 .x C_ 2009

de Chardin PT (1959) The phenomenon of man. Collins, London, UK

Edwards SD (2019) Empirical and heuristic phenomenological case study of the heartmath global coherence initiative. Int J Environ Res Public Health 16:1245. https://doi.org/10.3390/ijerph1607 1245

Fetters MD, Curry LA, Creswell JW (2017) Achieving integration in mixed methods designs-Principles and practices. Health Serv Res J 48:2134-2156

Lindhard T (2019) Consciousness from the outside-in and inside-out perspective. J Conscious Explor Res 10(3):1-15

McCraty R, Atkinson M, Timofejeva I, Joffe R, Vainoras A, Landauskas M, Alabdulgader AA, Ragulskis M (2018) The influence of heart coherence on synchronization between human heart rate variability and geomagnetic activity. J Complex Health Sci 1:42-48

Nelson R (2011) Detecting mass consciousness: effects of globally shared attention and emotion. J Cosmol 14:4616-4632

Wilber K (2000) Integral psychology. Shambhala: Boston, MA USA

Publisher's Note Springer Nature remains neutral with regard to jurisdictional claims in published maps and institutional affiliations. 